\title{
Chemical composition and antioxidant content of Thymus vulgaris honey and Origanum vulgare essential oil; their effect on carbon tetrachloride- induced toxicity
}

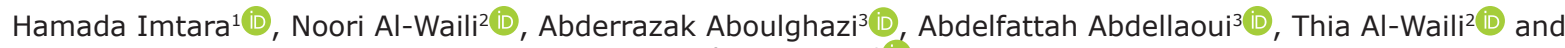 \\ Badiaa Lyoussi ${ }^{3}$ id \\ 1. Department of Biology and Biotechnology, Faculty of Arts and Sciences, Arab American University Palestine, P.O. Box \\ 240, Jenin, State of Palestine; 2. New York Medical Care for Nephrology, New York, USA; 3. Laboratory of Physiology, \\ Pharmacology and Environmental Health, Faculty of Sciences Dhar El Mehraz, BP 1796 Atlas, University Sidi Mohamed \\ Ben Abdallah, Fez 30 000, Morocco. \\ Corresponding author: Badiaa Lyoussi, e-mail: lyoussi@gmail.com \\ Co-authors: HI: hamada.tarayrah@gmail.com, NA: noori786@yahoo.com, AAb: abderazak1@gmail.com, \\ AAbd: abdellaouia@yahoo.fr, TA: dhia_waili@yahoo.com, \\ Received: 04-07-2020, Accepted: 08-12-2020, Published online: 30-01-2021
}

doi: www.doi.org/10.14202/vetworld.2021.292-301 How to cite this article: Imtara H, Al-Waili N, Aboulghazi A, Abdellaoui A, Al-Waili T, Lyoussi B (2021) Chemical composition and antioxidant content of Thymus vulgaris honey and Origanum vulgare essential oil; their effect on carbon tetrachloride-induced toxicity, Veterinary World, 14(1): 292-301.

\begin{abstract}
Aim: The study investigated the chemical composition, antioxidant content, and antioxidant activity of Thymus vulgaris honey (TVH) and Origanum vulgare essential oil (OVEO) and their mixture effect on carbon tetrachloride $\left(\mathrm{CCl}_{4}\right)$-induced toxicity.
\end{abstract}

Materials and Methods: The study conducted physicochemical characterization and chemical analysis of TVH and OVEO with the use of gas chromatography-mass spectrometry and high-performance liquid chromatograph (HPLC). The antioxidant activity of TVH and OVEO was done with the use of 1,2-diphenyl-1-picrylhydrazyl (DPPH) radical scavenging activity. The study used nine groups of rats to investigate the effect of TVH, OVEO, and a mixture of TVH and OVEO (HEM) on $\mathrm{CCl}_{4}$-induced toxicity. Intraperitoneal injection of $\mathrm{CCl}_{4}(1 \mathrm{~mL} / 100 \mathrm{~g})$ was used to induce toxicity. The doses of TVH and OVEO were $1 \mathrm{mg} / \mathrm{kg} . b . w t$, and $50 \mathrm{mg} / \mathrm{kg}$.b.wt, respectively. HEM contains TVH (1 mg/kg.b.wt) and OVEO (50 mg/kg.b.wt).

Results: TVH has a high content of phenols, flavonoids, and flavanols. HPLC analysis showed that TVH contains, for the $1^{\text {st }}$ time, epicatechin gallate, and at a high concentration. OVEO includes a high percentage of carvacrol and thymol. With the use of DPPH, OVEO was more potent than TVH. $\mathrm{CCl}_{4}$ caused significant liver and kidney damage and lipid disorders, which were alleviated by HVT, OVEO, and HEM. HVT was more potent than OVEO $(p<0.05)$, and HEM was more potent than HVT and OVEO $(\mathrm{p}<0.05)$.

Conclusion: The study identified high content of epicatechin gallate for the $1^{\text {st }}$ time in TVH, and OVEO contains a high percentage of thymol and carvacrol. Epicatechin gallate might be useful as a marker for TVH. Mixing OVEO and TVH significantly potentiated their protection against $\mathrm{CCl}_{4}$-induced liver and kidney toxicity.

Keywords: antioxidants, carbon tetrachloride, Origanum vulgare essential oil, thymus honey, toxicity.

\section{Introduction}

A large amount of data showed that honey has biological activities such as antimicrobial, anti-inflammatory, antioxidant, and immune-modulatory activities [1-3]. Thymus vulgaris honey (TVH) and Origanum vulgar essential oil (OVEO) have important biological activities and have great potential to be introduced in the illness treatment. TVH is unifloral honey, which has antimicrobial activity and wound healing properties. It is useful in managing radiation-induced mucositis and xerostomia in head and neck cancer patients [4-6]. Honey has been mentioned

Copyright: Imtara, et al. Open Access. This article is distributed under the terms of the Creative Commons Attribution 4.0 International License (http://creativecommons.org/licenses/by/4.0/), which permits unrestricted use, distribution, and reproduction in any medium, provided you give appropriate credit to the original author(s) and the source, provide a link to the Creative Commons license, and indicate if changes were made. The Creative Commons Public Domain Dedication waiver (http://creativecommons.org/ publicdomain/zero/1.0/) applies to the data made available in this article, unless otherwise stated. in Holy books, the Talmud, the Bible, and the Quran as a healer of human diseases. In the Surat Al-Nahel (the Bee chapter), it says (translating the meaning): (And your LORD taught the bee to build its cells in the mountains, on the trees, and in men's habitations, then to eat of all the fruits of the earth and find with skill the spacious paths of its LORD, their issues from within their bellies, a drink of varying colors, wherein is healing for men, verily in this is a sign for those who give thought). O. vulgar is one of the species of Origanum. Herbs of this family are used to improve the flavor of foods. A recent review showed that $O$ vulgar has an anticancer, anti-inflammatory, antiproliferative, antibacterial, and hepatoprotective effect [7]. The kidney and liver are vital organs with a wide range of biological functions that include metabolism, transforming, transport, and clearance of toxic substances. Furthermore, the kidney affects blood electrolytes, bone metabolism, and bone marrow function, and the liver is involved in lipid metabolism. 
Carbon tetrachloride $\left(\mathrm{CCl}_{4}\right)$ is a volatile organic alkyl halogen, which is metabolized in the liver and generates trichloromethyl $\left(\mathrm{CCl}_{3}\right)$ and trichloromethyl peroxyl $\left(\mathrm{CCl}_{3} \mathrm{O}_{2}\right)$.

$\mathrm{CCl}_{4}$ is very toxic to the liver and kidney and used experimentally to induce liver and kidney damage. Others and we have found that honey has a protective effect against $\mathrm{CCl}_{4}$-induced liver and kidney toxicity [8-10]. Furthermore, honey increases urine output and creatinine clearance, and it has protection against lead-induced kidney and liver toxicity $[11,12]$. The hepatoprotective activity of $O$. vulgare leaves extract against $\mathrm{CCl}_{4}$-induced hepatotoxicity in rats has been reported [13]. However, no study investigated the effect of TVH or OVEO on $\mathrm{CCl}_{4}$-induced liver and kidney toxicity. Therefore, the present study examined the protective effect of TVH, OVOE, and their combination (HEM) against $\mathrm{CCl}_{4}$-induced toxicity in rats. It was well known that the chemical composition of various honey samples is different $[14,15]$. Therefore, the authors designed the study to identify the chemical components and antioxidant activity of OVEO and TVH collected in Morocco.

The study showed for the first time the presence of epicatechin gallate in TVH collected in Fez, Boulemane, Morocco, and the ability of TVH, OVEO, and $\mathrm{HEM}$ to protect against $\mathrm{CCl}_{4}$-induced liver and kidney damage.

\section{Materials and Methods}

\section{Ethical approval}

The ethical institutional committee, Faculty of Sciences Dhar El Mahraz, University Sidi Mohamed Ben Abdallah, Fez, Morocco, approved the protocol. All the experimental proceedings achieved in laboratory animals followed the internationally accepted standard guidelines for animal care. The authors tried to minimize animal suffering and the number of animals used.

\section{Study period and location}

This study was conducted in June month of 2017 at Sidi Mohamed Ben Abdellah University, Morocco.

\section{Honey samples}

The authors purchased honey (T. vulgaris, Zaitra; Arabic name) from beekeepers, Fez, Boulemane, Morocco. The honey sample was collected in 2015 and stored at room temperature $\left(22-24^{\circ} \mathrm{C}\right)$ until analysis.

\section{Essential oil extraction}

The aerial part of $O$. vulgare $\mathrm{L}$ plant was bought from the herbalist, Imouzzer, Boulemane, Morocco. The extraction of the essential oil was carried out by hydro-distillation in a Clevenger-type apparatus and was stored at $4{ }^{\circ} \mathrm{C}$ in the presence of anhydrous sodium sulfate.

\section{The physicochemical and antioxidant content of honey}

Free acidity, $\mathrm{pH}$, ash, electrical conductivity, and moisture were measured in the TVH samples.
The measurements were carried out according to the International Honey Commission IHC [16].

The color and melanoidins content was determined according to the method described by Naab et al. [17]. The mineral content was measured according to the method described by Terrab et al. [18]. The total phenol content was determined according to the method described by Singleton [19]. The result of phenol content was expressed as the mg gallic acid/100 g of honey. The total flavonoid content was determined according to the method described by Samatha et al. [20]. The flavonoid content was expressed as mg quercetin/100 g of honey (mg Eq $\mathrm{Q} / 100 \mathrm{~g})$. Total flavonol content was determined according to the method described by Sugathakumar et al. [21]. The flavonol content was expressed as mg quercetin equivalent per $100 \mathrm{~g}$ of the honey mass (mg $\mathrm{Eq} \mathrm{Q} / 100 \mathrm{~g}$ ). The total antioxidant capacity was estimated by the phosphomolybdenum method according to the procedure described by Prieto et al. [22]. Total antioxidant capacity content was expressed as $\mathrm{mg}$ of ascorbic acid equivalent per $100 \mathrm{~g}$ of the honey mass (mg AA/100g).

\section{Antioxidant activity of TVH and OVEO}

The antioxidant activity of TVH and OVEO was determined with the use of 1,2-diphenyl-1-picrylhydrazyl (DPPH) radical scavenging activity according to the method by Brand-Williams et al. [23]. Briefly, the ethanol solution of DPPH solution was added to dilution series of TVH and OVEO ranging from 15 to 500 for TVH and 0.8 to $100 \mathrm{mg} / \mathrm{mL}$ for OVEO and then incubated in the dark for $1 \mathrm{~h}$. The absorbance was measured at $517 \mathrm{~nm}$. The experiment was performed in triplicates, and average absorption was recorded for each concentration. Butylated hydroxytoluene (BHT) was used as a standard. The percent inhibition of the DPPH radical by the samples was calculated based on the following formula:

(The absorbance of negative control - The absorbance of the sample)/the absorbance of negative control) $\times 100$.

Based on each sample, $\mathrm{IC}_{50}$ was determined (concentration of samples able to scavenge $50 \%$ of DPPH free radicals).

Identification of phenolic compounds of TVH by high-performance liquid chromatograph (HPLC)

The honey sample was subjected to base hydrolysis and extracted with ethyl acetate (liquid-liquid extraction) described by Aljadi and Yousoff [24]. In brief, $10 \mathrm{~g}$ of honey were dissolved in acidified distal water, and the phenolic compounds were extracted with the use of ethyl acetate. The phenolic extract was passed in the rotavapor to remove the solvent, and then the dry phenolic extract was dissolved in $5 \mathrm{~mL}$ of methanol grade HPLC. With the use of HPLC, the analyses were carried out at $280 \mathrm{~nm}$ for phenolic compounds and operated at $30^{\circ} \mathrm{C}$ using a C18 column $(4.6 \mathrm{~mm} \times 150 \mathrm{~mm}) \times 5 \mathrm{~mm}$ in a thermal fisher 
apparatus. The injected volume was $20 \mu \mathrm{L}$. Pure compounds that were used as standards included caffeic acid, gallic acid, epicatechin gallate, coumaric acid, rosmarinic acid, ferulic acid, syringic acid, tannic acid, and pyrogallol. All the standards were dissolved in methanol and injected under the same chromatographic conditions as the honey extracts. Phenolic compounds of honey were identified by comparing their retention times with those of pure standards. The results were obtained in $\mathrm{mg} / 100 \mathrm{~g}$ of honey.

\section{Gas chromatography-mass spectrometry (GC/MS) analysis of OVEO}

Regarding GC/MS analysis, the OVOE sample was diluted in hexane with a dilution of 10:100. The analysis of volatile constituents was completed using GC/MS method (GC ULTRA S/N 20062969; Polaris QS/N 210729), equipped with an HP-5MS column nonpolar fused silica $(60 \mathrm{~m} \times 0.32 \mathrm{~mm}, 0.25 \mathrm{~mm}$ thickness). The temperature of the injector was $250^{\circ} \mathrm{C}$. The column temperature was programmed from 40 to $260^{\circ} \mathrm{C}$ at $2^{\circ} \mathrm{C} / \mathrm{min}$. The carrier gas was helium, the flow rate was $1 \mathrm{~mL} / \mathrm{min}$, and the volume of sample injected was $1 \mu \mathrm{L}$ of diluted oil. The identification of the components has been made by determination of their indices of retention Kovats index (Ki) compared to a Ki of a series of n-alkanes (C8-C20) and by comparing their mass spectra recorded with those stored in the database of the spectrometer (NIST MS Library v. 2.0, US Department of Commerce, California, USA), and the literature [25].

\section{Effect of TVH, OVEO, and their mixture in $\mathrm{CCl}_{4}^{-}$ induced toxicity}

Animals

Forty-five adult male Wister rats $(221 \pm 22 \mathrm{~g})$ were used. The animals were kept in a diffusely lit and temperature-controlled room with a diurnal $12 \mathrm{~h}$ light cycle, where the temperature $\left(25 \pm 1^{\circ} \mathrm{C}\right)$ and relative humidity $(55 \pm 5 \%)$ were kept constant. The animals were given free access to a standard laboratory diet and water before the experiments.

\section{Preparation of honey-essential oil mixture}

OVEO was dissolved in tween 80 , and TVH was dissolved in water, and they mixed with each other. One $\mathrm{mL}$ of HEM containing TVH $(1 \mathrm{~g} / \mathrm{kg}$.b.wt $)$ and OVEO (50 mg/kg.b.wt) was used and delivered to the animals by gavage.

\section{Study design}

The experimental animals received intraperitoneal injections of $\mathrm{CCl}_{4}(1 \mathrm{~mL} / 100$ g.b.wt $)$ dissolved in olive oil, $10 \%$ solution, twice per week for 2 weeks. The administration of TVH, OVEO, and HEM was started on the $1^{\text {st }}$ day of $\mathrm{CCl}_{4}$ administration and was continued for 2 weeks.

The animals were randomly divided into nine groups, five animals each, as follows:

- Group I (water): The animals received drinking water $1 \mathrm{~mL} / \mathrm{kg}$.b.wt every day by gavage
- Group II (Tween 80): The animals received Tween $80(2 \%)$ by gavage $(1 \mathrm{~mL} / \mathrm{kg} . \mathrm{b} . \mathrm{wt})$ every day

- Group III (TVH): The animals received TVH by gavage ( $1 \mathrm{~g} / \mathrm{kg}$. b.wt) every day

- Group IV (OVEO): The animals received OVEO by gavage $(50 \mathrm{mg} / \mathrm{kg} . \mathrm{b} . \mathrm{wt})$ every day

- Group V (HEM): The animals received HEM 1 $\mathrm{mL} / \mathrm{kg}$.b.wt by gavage every day

- Group VI $\left(\mathrm{CCl}_{4}\right)$ : The animals received $\mathrm{CCl}_{4}$

- Group VII $\left(\mathrm{CCl}_{4}+\mathrm{TVH}\right)$ : The animals received $\mathrm{CCl}_{4}$ and treated with TVH by gavage at a dose of $1 \mathrm{~g} / \mathrm{kg} . \mathrm{b} . w \mathrm{wt}$ every day

- Group VIII ( $\left.\mathrm{CCl}_{4}+\mathrm{OVEO}\right)$ : The animals received $\mathrm{CCl}_{4}$ and treated with OVEO by gavage at a dose of $50 \mathrm{mg} / \mathrm{kg}$.b.wt every day

- Group IX (CCl4 + HEM): The animals received $\mathrm{CCl} 4$ and treated with HEM by gavage every day.

The doses of TVH, OVEO, and Tween 80 were used according to the previous publications $[12,26,27]$. At the end of the treatment period ( 2 weeks), the animals were sacrificed. Blood samples were collected in centrifuge tubes without anticoagulants and allowed to clot. The clotted blood was centrifuged at $4000 \times \mathrm{g}$ for $20 \mathrm{~min}$. Serum was separated for biochemical analyses.

\section{Statistical analysis}

Results were expressed as mean \pm SD. Statistical analysis was carried out by ANOVA with the use of GraphPad Prism (San Diego, California, USA) 6.0 program. $\mathrm{p}<0.05$ was considered significant.

\section{Results}

\section{Physicochemical properties of HTV and OVEO}

The physicochemical parameters of honey showed that the $\mathrm{pH}$ was $3.90 \pm 0.01$; free acidity was $37.93 \pm 2.25 \mathrm{mEq} / \mathrm{kg}$, moisture was $16.4 \pm 0.01 \%$, electric conductivity was $449 \pm 1731 \mu \mathrm{S} / \mathrm{cm}$, ash was $0.24 \pm 0.01 \%$, and melanoidin was $1.10 \pm 0.02$. The Pfund scale value was $0.33 \pm 0.01$, which indicated that the color was dark amber.

Mineral content analysis of honey showed that the concentration of potassium was $829.55 \pm 0.51 \mathrm{mg} / \mathrm{kg}$, sodium was $256.32 \pm 0.15 \mathrm{mg} / \mathrm{kg}$, magnesium was $61.47 \pm 0.21 \mathrm{mg} / \mathrm{kg}$, and calcium was $166.22 \pm 0.09 \mathrm{mg} / \mathrm{kg}$. OVEO analysis showed that the $\mathrm{pH}$ was 5.02 , density was $0.9484 \mathrm{~g} / \mathrm{mL}$, and the refractive index was 1.5153 .

\section{Phenol, flavonoid, and flavonol content of TVH}

The phenol content value was $74.05 \pm 1.21 \mathrm{mg}$ AGE/100 g, flavonoids content was $59.34 \pm 1.08 \mathrm{mg}$ $\mathrm{Eq} \mathrm{Q} / 100 \mathrm{~g}$, and flavonol was $15.08 \pm 0.04 \mathrm{mg} \mathrm{Eq}$ $\mathrm{Q} / 100 \mathrm{~g}$.

The honey was analyzed through HPLC under the same chromatographic conditions (Figure-1). The analysis showed that the concentration of caffeic acid was $0.033 \pm 0.00 \mathrm{mg} / 100 \mathrm{~g}$, ferulic acid was $0.68 \pm 0.021 \mathrm{mg} / 100 \mathrm{~g}$, gallicacidwas $2.86 \pm 0.046 \mathrm{mg} / 100 \mathrm{~g}$, 
epicatechin gallate was $6.91 \pm 0.05 \mathrm{mg} / 100 \mathrm{~g}$, and pyrogallol was $3.5 \pm 0.09 \mathrm{mg} / 100 \mathrm{~g}$. The analysis of honey did not show syringic acid, tannic acid, coumaric acid, or rosmoric acid.

\section{Antioxidant activity of TVH and OVEO}

The total antioxidant capacity of TVH was $163.51 \pm 8.55 \mathrm{mg}$ Eq AA $/ \mathrm{g}$. The IC50 value of BHT was $0.009 \pm 0.0001 \mathrm{mg} / \mathrm{mL}$ in the DPPH assay. However, the $\mathrm{IC}_{50}$ amount of OVEO was $0.30 \pm 0.02 \mathrm{mg} / \mathrm{mL}$ and of TVH was $10.85 \pm 0.02$, which means that the DPPH scavenging activity of OVEO was higher than that of TVH $(\mathrm{p}<0.05)$.

\section{GC/MS analysis OVEO}

Table-1 showed the results of the GC/MS analysis of OVEO. The study showed the presence of 26 compounds, and $92.45 \%$ of essential oil has been identified. The major constituents of the oil were carvacrol $(48.38 \%)$, thymol $(26.55 \%), \gamma$-terpinene (7.9\%), and 1,8-Cineol (4.86\%).

\section{The effect of TVH, OVEO, and HEM on $\mathrm{CCl}_{4}$-induced toxicity}

The effect of TVH, OVOE, and HEM on kidney and liver function and lipid profile in $\mathrm{CCl}_{4}$-untreated rats is demonstrated in Table-2. TVH decreased aspartate aminotransferase (AST) and alanine aminotransferase $(A L T)(p<0.05)$ significantly. TVH and

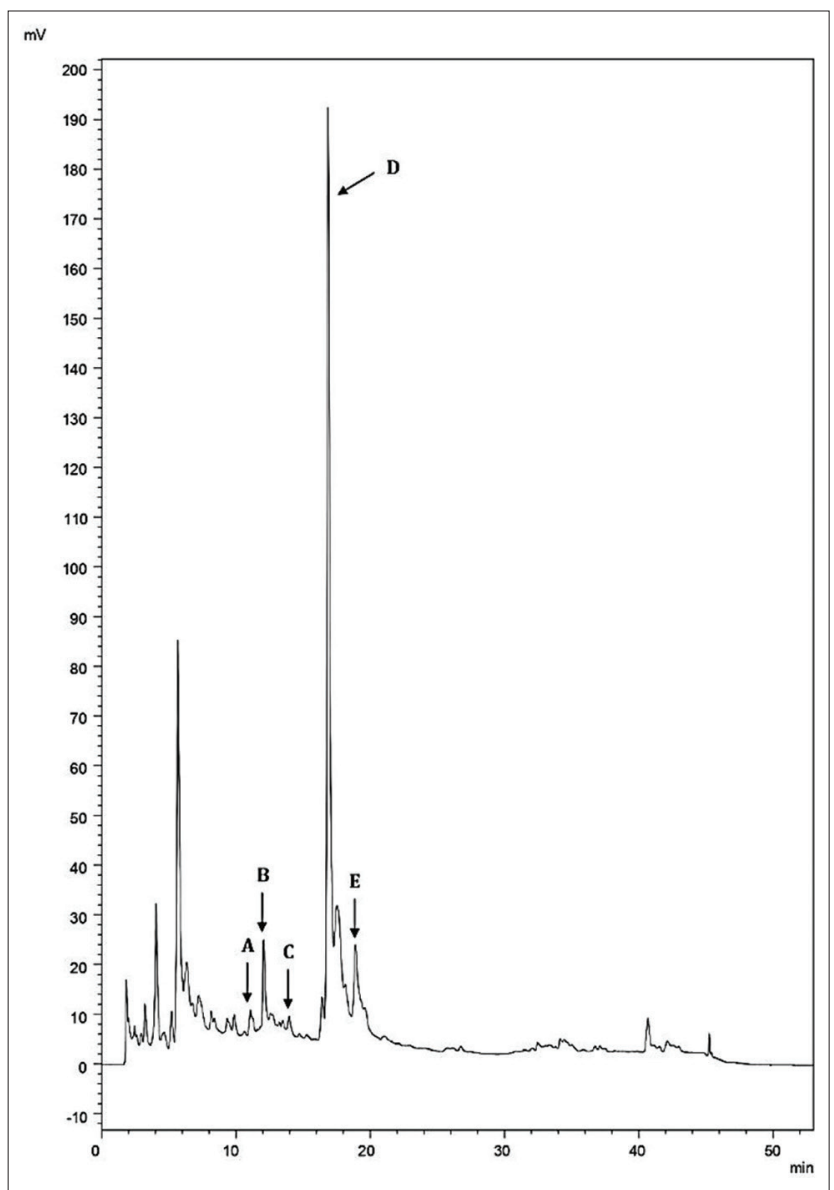

Figure-1: Chromatogram of Thymus vulgaris honey with identified standard compounds. A: Caffeic acid; B: Ferulic acid; C: Gallic acid; D: Epicatechin gallate; E: Pyrogallol.
OVEO did not cause significant changes in the total protein, total bilirubin, direct bilirubin, lipid parameters, kidney function, and potassium and calcium level. However, OVEO caused a significant elevation of sodium level compared to the control group $(p<0.05)$. HEM caused a significant lowering of AST, ALT, alkaline phosphatase (AP), and significantly increased total protein compared to the control group $(\mathrm{p}<0.05)$. Regarding the renal function and electrolytes, TVH, OVEO, and HEM did not cause significant changes in blood urea, creatinine, sodium, potassium, and calcium. Lipid assay showed that HEM lowered total cholesterol (TC), low-density lipoproteins (LDL), and very LDL (VLDL) and elevated high-density lipoprotein (HDL) compared to the control; the changes in TC level were significant $(\mathrm{p}<0.05)$.

In $\mathrm{CCl}_{4}$-treated rats, $\mathrm{CCl}_{4}$ caused a significant elevation of AST, ALT, AP, and total and direct bilirubin, and caused a significant lowering of total protein $(\mathrm{p}<0.05) \quad($ Table-3). TVH, OVOE, and HEM significantly ameliorated these changes. TVH was more potent than OVEO, and HEM was more potent than TVH and OVEO individually $(\mathrm{p}<0.05)$. Regarding kidney function and serum electrolytes, $\mathrm{CCl}_{4}$ significantly elevated blood urea, creatinine, sodium, potassium, and calcium, while TVH, OVOE, and HEM significantly decreased all these parameters.

TVH was more potent than OVOE, and HEM was more potent than TVH and OVOE $(p<0.05)$. Lipid assays revealed that $\mathrm{CCl}_{4}$ significantly increased all

Table-1: Chemical composition of Origanum vulgare essential oil from Morocco.

\begin{tabular}{lcc}
\hline Compounds & \% Area & Kovats index \\
\hline$\alpha$-Pinene & 0.10 & 948 \\
2-Carene & 0.15 & 1002 \\
$\alpha$-Phellandrene & 0.03 & 1007 \\
3-Carene & 0.30 & 1009 \\
1,4-Cineol & 0.06 & 1012 \\
$\alpha$-Terpinene & 0.81 & 1018 \\
1,8-Cineol & 4.86 & 1038 \\
Cis-Ocimene & 0.03 & 1072 \\
$\gamma$-Terpinene & 7.90 & 1084 \\
Terpinolene & 0.06 & 1096 \\
Isoborneol & 0.59 & 1158 \\
$\beta$-terpineol & 0.07 & 1162 \\
Borneol & 0.23 & 1172 \\
4-terpinol & 0.15 & 1235 \\
Cis-carveol & 0.07 & 1289 \\
Thymol methyl ether & 0.29 & 1325 \\
Pulegone & 0.05 & 1335 \\
Thymol & 26.55 & 1375 \\
Carvacrol & 48.38 & 1394 \\
Caryophyllene & 1.03 & 1426 \\
$\alpha$-Himachalene & 0.15 & 1475 \\
Longifolene-(V4) & 0.06 & 1495 \\
$\alpha$-Cadinene & 0.05 & 1538 \\
$\gamma$-Muurolene & 0.11 & 1542 \\
$\gamma$-Cadinene & 0.28 & 1571 \\
Caryophyllene oxide & 0.09 & 1628 \\
Total & 92.45 & \\
\hline
\end{tabular}


Table-2: Effect of Thymus vulgaris honey, Origanum vulgar essential oil and HEM on liver, kidney function, and lipid profile in $\mathrm{CCl} 4$-untreated rats.

\begin{tabular}{|c|c|c|c|c|c|c|}
\hline \multirow[t]{2}{*}{ Variables } & \multicolumn{5}{|c|}{ Treatment groups } & \multirow[t]{2}{*}{ F/P value } \\
\hline & Control & Tween 80 & $\begin{array}{c}\text { Thymus vulgaris } \\
\text { honey }\end{array}$ & $\begin{array}{c}\text { Origanum vulgar } \\
\text { essential oil }\end{array}$ & HEM & \\
\hline AST (U/L) & $131.0 \pm 2.6$ & $140.0 \pm 7.7^{*}$ & $120.0 \pm 3.4 * \#$ & $123.0 \pm 3 \#$ & $100.0 \pm 3.0 * \#+\beta$ & $57.81 / 0.000$ \\
\hline ALT $(U / L)$ & $124.0 \pm 2.9$ & $133.0 \pm 4.7$ & $112.0 \pm 9.0 * \#$ & $126.0 \pm 1.5 \#+$ & $109.0 \pm 4.63 * \# \beta$ & $18.66 / 0.00$ \\
\hline $\operatorname{ALKP}(U / L)$ & $137.0 \pm 4.5$ & $147.0 \pm 3.4^{*}$ & $139.0 \pm 3.4 \#$ & $141.0 \pm 2.8$ & $122.0 \pm 2.0 * \#+\beta$ & $39.03 / 0.00$ \\
\hline Total protein $(\mathrm{g} / \mathrm{dl})$ & $6.5 \pm 0.07$ & $6.4 .0 \pm 0.22$ & $6.6 \pm 0.15$ & $6.3 \pm 0.15+$ & $6.8 \pm 0.11 * \# \beta$ & $8.37 / 0.0004$ \\
\hline Total Bilirubin (mg/dl) & $0.15 \pm 0.07$ & $0.20 \pm 0.03$ & $0.14 \pm 0.01$ & $0.17 \pm 0.05$ & $0.11 \pm 0.02 \#$ & $3.21 / 0.034$ \\
\hline Direct Bilirubin (mg/l) & $0.1 \pm 0.02$ & $0.13 \pm 0.06$ & $0.09 \pm 0.04$ & $0.11 \pm 0.02$ & $0.08 \pm 0.03$ & $1.34 / 0.28$ \\
\hline Cholesterol (mg/dl) & $71.0 \pm 10.0$ & $80.0 \pm 6.0$ & $71.0 \pm 8.0$ & $84.0 \pm 2.0$ & $52.0 \pm 7.0 * \#+\beta$ & $15.04 / 0.00$ \\
\hline Triglycerides (mg/dl) & $39.0 \pm 6.0$ & $43.0 \pm 5.0$ & $37.0 \pm 11.0$ & $47.0 \pm 25.0$ & $26.0 \pm 9.0 \beta$ & $3.217 / 0.034$ \\
\hline $\mathrm{HDL}(\mathrm{mg} / \mathrm{dl})$ & $22.0 \pm 2.0$ & $20.0 \pm 2.0$ & $22.0 \pm 3.0$ & $22.0 \pm 4.0$ & $24.0 \pm 1.0$ & $1.47 / 0.248$ \\
\hline LDL (mg/dl) & $41.0 \pm 9.0$ & $52.0 \pm 12.0$ & $42.0 \pm 8.0$ & $53.0 \pm 16.0$ & $23.0 \pm 8.0 \# \beta$ & $5.98 / 0.002$ \\
\hline $\operatorname{VLDL}(\mathrm{mg} / \mathrm{dl})$ & $8.0 \pm 1.0$ & $9.0 \pm 1.0$ & $7.0 \pm 2.0$ & $9.0 \pm 5.0$ & $5.0 \pm 2.0$ & $2.00 / 0.133$ \\
\hline Creatinine $(\mathrm{mg} / \mathrm{dl})$ & $0.34 \pm 0.04$ & $0.39 \pm 0.01$ & $0.38 \pm 0.04$ & $0.38 \pm 0.03$ & $0.34 \pm 0.02$ & $2.30 / 0.93$ \\
\hline Urea (mg/dl) & $24.0 \pm 2.0$ & $26.0 \pm 2.0$ & $23.0 \pm 1.0$ & $24.0 \pm 3.0$ & $20.0 \pm 1.0 * \# \beta$ & $6.315 / 0.019$ \\
\hline Sodium $(\mathrm{mmol} / \mathrm{l})$ & $127.0 \pm 2.6$ & $128.0 \pm 3.6$ & $129.0 \pm 1.5$ & $136.0 \pm 4.9 * \#$ & $129.0 \pm 5.8$ & $3.987 / 0.014$ \\
\hline Potassium (mmol/l) & $4.3 \pm 1.15$ & $4.4 \pm 1.38$ & $4.6 \pm 0.76$ & $4.9 \pm 0.35$ & $4.0 \pm 0.6$ & $0.713 / 0.59$ \\
\hline Calcium (mg/dl) & $7.3 \pm 0.49$ & $7.4 \pm 0.26$ & $7.7 \pm 0.3$ & $7.3 \pm 0.32$ & $7.2 \pm 0.28$ & $1.522 / 0.233$ \\
\hline
\end{tabular}

$* p<0.05$ in comparison to Group $1, \# p<0.05$ in comparison to Group 2, $+p<0.05$ in comparison to Group 3, $\beta p<0.05$ in comparison to Group 4. HDL=High-density lipoprotein, VLDL=Very low-density lipoproteins, LDL=Low-density lipoproteins

Table-3: Effect of Thymus vulgaris honey, Origanum vulgar essential oil and HEM on liver, kidney function, and lipid profile in $\mathrm{CCl} 4$-treated rat.

\begin{tabular}{|c|c|c|c|c|c|c|}
\hline \multirow[t]{2}{*}{ Variables } & \multicolumn{5}{|c|}{ Treatment groups } & \multirow[t]{2}{*}{ F/P value } \\
\hline & Control & $\mathrm{CCl} 4$ & $\begin{array}{c}\text { Thymus } \\
\text { vulgaris honey }\end{array}$ & $\begin{array}{l}\text { Origanum vulgar } \\
\text { essential oil }\end{array}$ & HEM & \\
\hline AST (U/L) & $131.0 \pm 3.0$ & $246.0 \pm 8.0 *$ & $214.0 \pm 9.95 * \#$ & $228.0 \pm 7.5^{*} \#+$ & $156.0 \pm 3.0 * \#+\beta$ & $248.785 / 0.000$ \\
\hline ALT (U/L) & $124.0 \pm 3.0$ & $192.0 \pm 2.1^{*}$ & $145.0 \pm 7 * \#$ & $166.0 \pm 5.7^{*} \#+$ & $121.0 \pm 7.6 * \#+\beta$ & $191.82 / 0.00$ \\
\hline ALKP (U/L) & $137.0 \pm 4.5$ & $314.0 \pm 3.05 *$ & $252.0 \pm 5.29 * \#$ & $288.0 \pm 6 * \#+$ & $166.0 \pm 3^{*} \#+\beta$ & $1488.6 / 0.00$ \\
\hline $\begin{array}{l}\text { Total } \\
\text { protein (g/dl) }\end{array}$ & $6.5 \pm 0.07$ & $4.9 \pm 1.55^{*}$ & $6 \pm 1.03 * \#$ & $4.9 \pm 2.0 * \#+$ & $6.3 \pm 1.5^{*} \#+\beta$ & $1.557 / 0.22$ \\
\hline $\begin{array}{l}\text { Total } \\
\text { bilirubin (mg/dl) }\end{array}$ & $0.15 \pm 0.07$ & $0.96 \pm 0.05^{*}$ & $0.36 \pm 0.03 * \#$ & $0.49 \pm 0.04 * \#+$ & $0.28 \pm 0.08 * \# \beta$ & $149.0 / 0.00$ \\
\hline $\begin{array}{l}\text { Direct } \\
\text { bilirubin (mg/l) }\end{array}$ & $0.1 \pm 0.02$ & $0.51 \pm 0.04 *$ & $0.3 \pm 0.03 * \#$ & $0.38 \pm 0.05^{*} \#+$ & $0.21 \pm 0.05^{*} \#+\beta$ & $78.0 / 0.00$ \\
\hline $\begin{array}{l}\text { Cholesterol } \\
(\mathrm{mg} / \mathrm{dl})\end{array}$ & $71.0 \pm 10.0$ & $107.0 \pm 3.0 *$ & $73.0 \pm 2.0 * \#$ & $85.0 \pm 3.0 * \#+$ & $61.0 \pm 6.0 * \#+\beta$ & $49.177 / 0.00$ \\
\hline $\begin{array}{l}\text { Triglycerides } \\
(\mathrm{mg} / \mathrm{dl})\end{array}$ & $39.0 \pm 6.0$ & $62.0 \pm 11.0 *$ & $49.0 \pm 2.0 \#$ & $55.0 \pm 2.0 *$ & $38.0 \pm 3.0 \# \beta$ & $15.27 / 0.00$ \\
\hline $\mathrm{HDL}(\mathrm{mg} / \mathrm{dl})$ & $22.0 \pm 2.0$ & $16.0 \pm 1.0 *$ & $22.0 \pm 2.0 \#$ & $19.0 \pm 1.0 * \#+$ & $22.0 \pm 1.0 \# \beta$ & $16.36 / 0.00$ \\
\hline $\mathrm{LDL}(\mathrm{mg} / \mathrm{dl})$ & $41.0 \pm 9.0$ & $78.0 \pm 4.0 *$ & $40.0 \pm 9 \#$ & $58.0 \pm 8.0 * \#+$ & $32.0 \pm 5.0 \#+\beta$ & $31.66 / 0.00$ \\
\hline VLDL (mg/dl) & $8.0 \pm 1.0$ & $12.0 \pm 2.0$ & $10.0 \pm 2.0$ & $11.0 \pm 5.0$ & $8.0 \pm 1.0$ & $2.285 / 0.09$ \\
\hline $\begin{array}{l}\text { Creatinine (mg/ } \\
\text { dl) }\end{array}$ & $0.34 \pm 0.04$ & $0.61 \pm 0.05^{*}$ & $0.47 \pm 0.06 * \#$ & $0.50 \pm 0.05 * \#$ & $0.46 \pm 0.02 * \#$ & 20.4/0.00 \\
\hline Urea (mg/dl) & $24.0 \pm 2.0$ & $42.0 \pm 1.0 *$ & $33.0 \pm 2.0 * \#$ & $34.0 \pm 1.0 * \#$ & $30.0 \pm 1.0 * \#+\beta$ & $97.27 / 0.00$ \\
\hline $\begin{array}{l}\text { Sodium } \\
(\mathrm{mmol} / \mathrm{l})\end{array}$ & $127.0 \pm 2.6$ & $162.0 \pm 1.15^{*}$ & $140.0 \pm 0.71 * \#$ & $146.0 \pm 3.54 * \#+$ & $134.0 \pm 2.6 \#+\beta$ & $123.0 / 0.00$ \\
\hline $\begin{array}{l}\text { Potassium } \\
(\mathrm{mmol} / \mathrm{l})\end{array}$ & $4.3 \pm 1.15$ & $8.5 \pm 1.54 *$ & $6.5 \pm 0.7$ & $6.9 \pm 1.7 *$ & $4.6 \pm 0.65 \# \beta$ & $9.93 / 0.0001$ \\
\hline $\begin{array}{l}\text { Calcium } \\
(\mathrm{mg} / \mathrm{dl})\end{array}$ & $7.3 \pm 0.49$ & $10.2 \pm 0.35^{*}$ & $8.9 \pm 0.06 * \#$ & $8.6 \pm 0.26 * \#$ & $7.9 \pm 0.36 \#+$ & $34.83 / 0.00$ \\
\hline
\end{tabular}

the lipid parameters and decreased HDL significantly. However, TVH, OVOE, and HEM significantly lowered the elevated lipid parameters as well as elevated the lowered HDL. TVH was more potent than OVOE, and HEM was more potent than TVH and OVOE $(p<0.05)$.

\section{Discussion}

The data presented here demonstrated for the first time the presence of epicatechin gallate in Moroccan TVH and the protective effect of $\mathrm{TVH}, \mathrm{OVEO}$, and their combination against $\mathrm{CCl}_{4}$ 
induced liver and kidney damage. TVH was more potent than $\mathrm{OVOE}$ to protect against $\mathrm{CCl}_{4}$ toxicity, and HEM was more potent than TVH and OVOE individually.

The $\mathrm{pH}$ of TVH was $3.90 \pm 0.01$, which was less than the $\mathrm{pH}$ of Ceratonia siliqua honey samples (range from 4.17 to 5.05) collected from Morocco [28]. Furthermore, it was less than the $\mathrm{pH}$ of TVH collected from other different areas in Morocco; Rachidia 4.51 \pm 0.02 , Saouira 4.04 \pm 0.03 , and Zaraphyt $4.36 \pm 0.02$ [29]. It means that TVH collected from Fez, boulemane, was more acidic. However, the $\mathrm{pH}$ value was within the range of $\mathrm{pH}$ of French honey (3.466.48), Uruguayan honey (3.0-4.3), Portuguese honey (3.98-5.05), and Iranian honey (3.62-6.61) [30-32]. The $\mathrm{pH}$ of honey could be affected by the method of extraction and time of storage.

Other compositions, including water content, ash, and electrical conductivity, are almost within the range found in $C$. siliqua honey collected from Morocco [28].

The ash content and electrical conductivity correlated with the mineral content of honey [33]. The ash content was $0.24 \pm 0.01 \%$, which is following the standards of ash content in honey used in the EU (ash percentage of honey $<0.6 \%$ ). Furthermore, the ash content of TVH lies in the range of Iranian honey samples (0.041-0.562\%) and Indian honey samples (0.03$0.43 \%)[30,34]$.

The electrical conductivity of TVH was $449 \pm 1.73 \mu \mathrm{S} / \mathrm{cm}$. According to the EU, the maximum limit value of electrical conductivity for thyme honey is $800 \mu \mathrm{S} / \mathrm{cm}$ [35]. The electrical conductivity of TVH lies in the range of Iranian honey (210 and $1120 \mu \mathrm{S} / \mathrm{cm})$, Spanish honey (89 and $1213 \mu \mathrm{S} / \mathrm{cm}$ ), and Indian honey (330 and $940 \mu \mathrm{S} / \mathrm{cm})[30,36]$. It was found that electrical conductivity has a correlation with the mineral content of honey, and it is usually used for routine honey quality control and to determine its botanical origin $[33,37]$.

The honey moisture content is an important criterion to determine the quality of honey. The water content depends on nectar, storage and environmental conditions, and harvest season. TVH moisture was $16.4 \pm 0.01 \%$, and it was within the range of Iranian honey moisture (13.97-17\%), Portuguese honey moisture (13.1 and 16.9), and within limits $(\leq 20 \%)$ set by the EU $[30,32,34,35]$. The differences observed between the samples might be related to environmental conditions, harvest period, and degree of honey maturity [35].

The mineral content is an essential part of the nutritional values of honey. The results showed that TVH contains necessary minerals that involve in several vital functions of the animals and the human body. It was found that potassium was the most abundant element in the thyme honey. The range of potassium concentration in TVH is almost within the range obtained in other honey types collected from different countries $[29,36]$. Another study showed that potassium made up $73 \%$ of 18 different minerals in ten mono-floral kinds of honey [33]. Furthermore, a positive relationship between mean conductivity and total mineral content and $\mathrm{pH}$ and total mineral content was observed [33]. The mineral content is used as a parameter in determining the botanical and geographical origins of honey $[16,17]$.

The Pfund scale value of TVH was $0.33 \pm$ 0.01 , which indicated that the color was dark amber. The color is similar to carob honey and Portuguese honey [29,37]. The color depends on antioxidants, minerals, and pollen content [29].

Phenolic compounds are plant-derived secondary metabolites and transferred through the nectar to the honey. The phenolic compounds can be classified into phenolic acids and flavonoids. The content of phenolic compounds of honey depends on the floral and geographical origins [14].

The value of phenol content in TVH was $74.05 \pm 1.21 \mathrm{mg} \mathrm{GAE} / 100 \mathrm{~g}$. It was found that phenol content of 17 commercial honey samples from Morocco varied from $16.38 \mathrm{mg} \mathrm{GAE} / 100 \mathrm{~g}$ in citrus honey to $92.37 \mathrm{mg}$ GAE/100 in thyme honey from Rachidia [27]. Therefore, the phenol content in TVH was less than that in thyme honey collected from Rachidia, Morocco. Iranian honey showed higher total phenol content (ranged between $193.8 \mathrm{mg}$ GAE/100 $\mathrm{g}$ and $3020 \mathrm{mg}$ GAE/100 g) than TVH [30]. The total phenolic content of honey samples collected from Greek ranged from 55 to 92 mg GAE/100 g, and Manuka honey had a phenolic content (71 mg GAE/100g) [38]. Total phenolic content of 12 different Mediterranean floral sources in Jordan ranged between $33.7 \mathrm{mg} \mathrm{GAE} / 100 \mathrm{~g}$ and 86.3 $\mathrm{mg} \mathrm{GAE} / 100 \mathrm{~g}$ [39]. Therefore, the phenolic content of TVH lies within the range of Jordanian honey and Greek honey samples, and it is almost similar to Manuka honey.

With the use of HPLC, the standard compounds were detected at $280 \mathrm{~nm}$ because most of the phenolic compounds showed reasonably high absorbance at this value. Five phenolic compounds were identified in TVH extract: Ferulic acid, gallic acid, caffeic acid, epicatechin gallate, and pyrogallol. The major constituent in the sample was epicatechin gallate, with a concentration of $6.91 \pm 0.05 \mathrm{mg} / 100 \mathrm{~g}$. Ferulic acid, gallic acid, and caffeic acid have been reported in Malaysian honey [24]. Twenty-eight samples of thyme honey collected from Greek were analyzed, and a total of 62 compounds were isolated. Thyme honeys contains various compounds such as phenylacetaldehyde, 1-phenyl-2,3-butanedione, 3-hydroxy-4-phenyl-2-butanone, 3-hydroxy-1-phenyl-2-butanone, phenylacetonitrile, and carvacrol [40]. However, no epicatechin gallate was detected. In another study, six phenolic acids (gallic, syringic, benzoic, trans-cinnamic, p-coumaric, and caffeic acids) and five flavonoids (catechin, kaempferol, naringenin, luteolin, and 
apigenin) were identified in Malaysian Tualang, Gelam, and Borneo tropical honey [41].

Epicatechin gallate was detected for the first time in TVH. Epicatechin gallate was not detected in honey before. It is useful in treating wounds, and it exhibits a potent anti-inflammatory and analgesic effect by lowering levels of plasma prostaglandin E2, tumor necrosis factor- $\alpha$, interleukin- $1 \beta$ (IL-1 $\beta$ ), and IL-6 [42-44]. Therefore, epicatechin gallate in the TVH makes it a potential agent to be used in wounds and inflammation. Furthermore, as epicatechin gallate was not found in other honey, it might be a useful marker for TVH from Morocco.

The value of flavonoid content was $59.34 \pm 1.08 \mathrm{mg}$ $\mathrm{QE} / 100 \mathrm{~g}$, and flavonol was $15.08 \pm 0.04 \mathrm{mg} \mathrm{QE} / 100 \mathrm{~g}$. Flavonoid content was $0.42 \mathrm{mg} \mathrm{QE} / 100 \mathrm{~g}$ in citrus honey and $13.962 \mathrm{mg} \mathrm{QE} / 100 \mathrm{~g}$ in black cumin honey [29]. Therefore, the flavonoid content of TVH was higher than that found in citrus honey as well as black cumin honey.

The total antioxidant capacity of TVH was $163.51 \pm 8.55 \mathrm{mg} \mathrm{Eq} \mathrm{AA} / \mathrm{g}$. The $\mathrm{IC}_{50}$ values of thyme honey from Rachidia, Morocco, were $52.85 \pm 1.2 \mathrm{mg} / \mathrm{mL}$, and from Saouira, Morocco, were $51.76 \pm 1.26 \mathrm{mg} / \mathrm{mL}[29]$. This means that the DPPH scavenging activity of THV was higher than that of thyme honey collected in different areas of Morocco. The $\mathrm{IC}_{50}$ values of 21 different types of honey, which were derived from the Olympus mountain area, Greek, ranged from 7.5 to $109.0 \mathrm{mg} / \mathrm{mL}$, while Manuka honey exhibited a weak antioxidant activity $\left(\mathrm{IC}_{50}\right.$; $68.0 \mathrm{mg} / \mathrm{mL}$ ) in DPPH assay [38]. Therefore, TVH was more potent than Manuka honey as an antioxidant and more than most Greek honey. $\mathrm{IC}_{50}$ of Malaysian Tualang, Gelam, and Borneo tropical honey ranged between $5.24 \pm 0.40$ and $17.51 \pm 0.51 \mathrm{mg} / \mathrm{mL}$, and therefore, the antioxidant activity of TVH lies in the same range [41]. Jordanian honey collected in summer from Umm Alyanabea location has $\mathrm{IC}_{50}=24.5 \mathrm{mg} / \mathrm{mL}$, which is weaker than TVH as an antioxidant. The use of DPPH to evaluate the antioxidant activity is based on determining the ability of TVH to act as a hydrogen or electron donor in the conversion of DPPH in its reduced form (DPPH-H).

The GC/MS analysis of OVOE revealed two major compounds: Carvacrol (48.38\%) and thymol (26.55\%), which agrees with another study [45]. Furthermore, the compounds demonstrated in the OVOE were similar to O. vulgare from Morocco and other countries, which showed that the major compound was carvacrol $[25,46]$. The percentage of carvacrol and thymol in the OVOE sample is twice as high as those identified in OVOE from other Morocco areas [25]. The difference might be related to the method of isolation, geographic origin, and season of harvesting [47]. It has been reported that 37 compounds were identified in the leaf-flower oils and included carvacrol $(30.73 \%)$, thymol $(18.81 \%)$, P-cymene (10.88\%), caryophyllene $(7.73 \%)$, and 3 -carene $(4.06 \%)$ [48]. Therefore, carvacrol and thymol contents were less than those found in the present study. In another study, seven components were identified in OVEO; $\alpha$-thujene, myrcene, $\alpha$-terpinene, o-cymene, $\gamma$-terpinene, thymol, and carvacrol; thymol content was $45 \%$, and carvacrol content was $37.4 \%$ [49].

The $\mathrm{IC}_{50}$ value of OVEO prepared from the aerial part (stem and leaves) of the plant was $0.30 \pm 0.02 \mathrm{mg} / \mathrm{mL}$. It is almost similar to the results of the IC50 values of the Chinese OVEO prepared from leaves/flower $(0.332 \pm 0.040 \mathrm{mg} / \mathrm{mL})$ and the plant root $(0.357 \pm 0.031 \mathrm{mg} / \mathrm{mL})$, but less than $\mathrm{IC}_{50}$ values of essential oil prepared from the plant stem $(0.501 \pm 0.029 \mathrm{mg} / \mathrm{mL})$ [48]. It was found that $\mathrm{IC}_{50}$ of OVEO ranged from $0.32 \mathrm{mg} / \mathrm{mL}$ to $0.76 \mathrm{mg} / \mathrm{mL}$, depending on incubation time [21]. However, the IC50 value of OVEO was less than that of TVH $(10.85 \pm 0.02 \mathrm{mg} / \mathrm{mL})$, which means that the DPPH scavenging activity of OVEO was higher than that of TVH.

The results showed that $\mathrm{CCl}_{4}$ significantly increases serum levels of AST, ALT, and ALP compared to the control group. However, administration of TVH, OVEO, or their combination to the animals with $\mathrm{CCl}_{4}$-induced hepatotoxicity decreased significantly liver enzymes compared to the $\mathrm{CCl}_{4}$ treated group. This finding showed the hepatoprotective effect of TVH, OVOE, and HEM. Interestingly, HEM showed a more profound hepatoprotective effect than TVH or OVEO. The potentiation of HEM effect might be due to the synergistic activity of natural ingredients in TVH and OVEO. It was found that $O$. vulgare leaf extract has significant protection against $\mathrm{CCl}_{4}$ induced hepatotoxicity in a dose-dependent manner. It lowered serum ALT, ALP, and AST levels and elevated Glutathione S-transferase, catalase, superoxide dismutase, glutathione peroxidase, glutathione reductase, and GSH levels in liver tissue [50]. Furthermore, others and we found that honey could protect the liver and kidney after $\mathrm{CCl}_{4}$ intoxication by normalizing liver enzymes and kidney function [8-10].

$\mathrm{CCl}_{4}$ significantly increased TG levels, cholesterol, and LDL and decreased serum levels of HDL compared to the control group. TVH, OVEO, and HEM markedly ameliorated these effects. This finding agrees with the impact of Sidr honey on lipid profile in $\mathrm{CCl}_{4}$ toxicity [8]. In $\mathrm{CCl}_{4}$-untreated rats, TVH or OVEO has no significant effect on lipid profile; however, their combination caused a considerably lower TC, LDL, and VLDL and considerable HDL elevation. This result is most likely due to an additive or synergistic effect of active ingredients in TVH and OVEO. This finding makes their combination a good candidate for prophylaxis of dyslipidemia and cardiovascular diseases.

$\mathrm{CCl}_{4}$ significantly increased the blood level of creatinine and urea. The mechanism of $\mathrm{CCl}_{4}$ induced renal toxicity is almost the same as that of the liver. Furthermore, $\mathrm{CCl}_{4}$ has a strong affinity to the kidney cortex because 


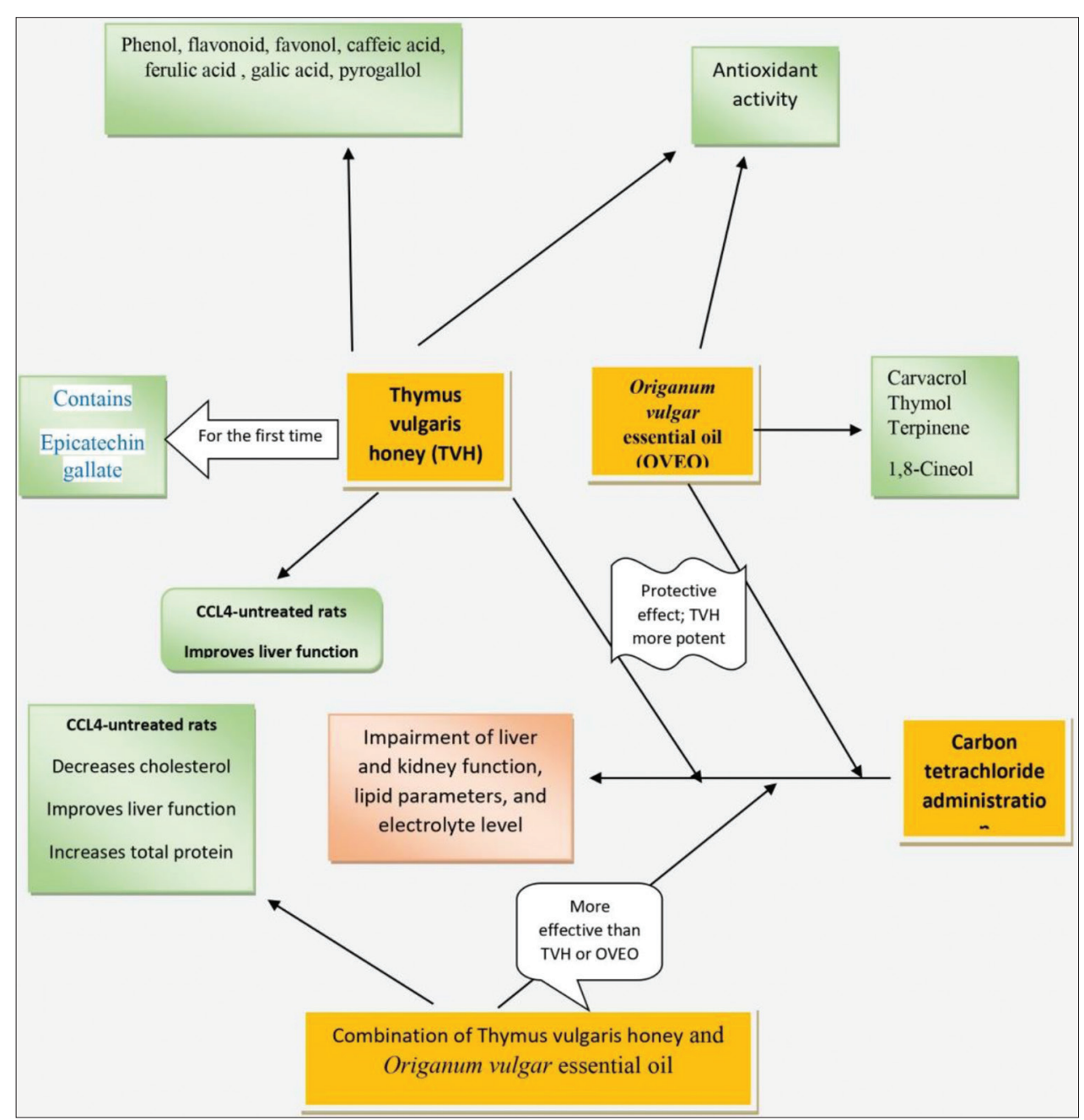

Figure-2: Main effects of thymus honey and Origanum vulgar essential oil.

it contains a high level of cytochrome P-450 [51]. The administration of TVH, OVEO, and their mixture significantly decreased the elevated levels of creatinine, urea, sodium, potassium, and calcium; the effect was more pronounced with HEM. Recently, we have found that $\mathrm{CCl}_{4}$ causes a significant elevation of oxidative stress markers in the blood and kidney tissues, which were markedly alleviated by Carob honey's administration (Unpublished).

TVH has a high content of epicatechin galatte and ferulic acid, while OVOE contains carvacrol and thymol. Epicatechin gallate has anti-inflammatory, analgesic, and wound healing properties $[42,43]$. Ferulic acid effectively reduced lipid disorders in the plasma, liver, and kidney of $\mathrm{CCl}_{4}$-treated rats [52]. Carvacrol is a phenolic monoterpenoid found in essential oils of $O$. vulgare, T. vulgaris, and other plants. A recent review showed that carvacrol has antioxidants, antimicrobial, and anti-inflammatory activity [53]. The mechanism of action of TVH, OVEO is most likely due to antioxidant capacity and anti-inflammatory activity, which are dependent on their active chemical ingredients, particularly thymol, carvacrol, epicatechin galatte, and ferulic acid.

\section{Conclusion}

The main finding of this study is summarized in Figure-2. Interestingly, the data showed for the first time that TVH contains a high level of epicatechine galatte, which makes it a marker for TVH. The analysis of the OVEO confirms the presence of two major compounds: carvacrol and thymol. HVT and OVEO exhibited a strong antioxidant activity and have a high capacity to scavenge the free-radical DPPH. Furthermore, TVH, OVEO, and HEM showed a significant protective effect against $\mathrm{CCl}_{4}$-induced liver and kidney damage, electrolyte disturbances, and lipid disorder. Although the ability of OVEO to scavenger DPPH was higher than TVH; TVH was more potent than OVEO to protect against $\mathrm{CCl}_{4}$ toxicity. Therefore, TVH, OVEO, and HEM are significant interventions to protect against chemical toxicity and might be useful in other causes of kidney and liver failure and dyslipidemia. While TVH and OVEO did not significantly affect kidney and liver function in $\mathrm{CCl}_{4}$ non-treated rats, their combination causes a substantial improvement in lipid profile and kidney and liver function. Therefore, the use of HEM in normal individuals might improve the lipid profile and liver and kidney function and protect against cardiovascular disease. These findings are exciting and will stimulate further preclinical and clinical studies in this growing field. 


\section{Authors' Contributions}

$\mathrm{HI}, \mathrm{AAb}, \mathrm{AAbd}$, and BL designed the experimental protocols and participated in the practical work and writing of the paper. NA analyzed the data and results and wrote the manuscript for publication. TA did the statistical analysis. All authors read and approved the final manuscript.

\section{Acknowledgments}

The authors want to thank Laboratory of Physiology, Pharmacology and Environmental Health, Faculty of Sciences, Dhar El Mehraz, Morocco, for providing the facilities to carry out the research work. The authors are also thankful to New York Medical Care for Nephrology, New York, USA, for providing financial support for the cost of the publication (Grant NYMCN-12-20-03).

\section{Competing Interests} interests.

The authors declare that they have no competing

\section{Publisher's Note}

Veterinary World remains neutral with regard to jurisdictional claims in published institutional affiliation.

\section{References}

1. Ahmed, S., Sulaiman, S.A., Baig, A.A., Ibrahim, M., Liaqat, S., Fatima, S., Jabeen, S., Shamim, N. and Othman, N.H. (2018) Honey as a potential natural antioxidant medicine: An insight into its molecular mechanisms of action. Oxid. Med. Cell. Longev., 2018: 8367846.

2. Al-Waili, N., Salom, K., Al-Ghamdi, A., Ansari, M.J., Al-Waili, A. and Al-Waili, T. (2013) Honey and cardiovascular risk factors, in normal individuals and in patients with diabetes mellitus or dyslipidemia. J. Med. Food, 16(12): 1063-1078.

3. Samarghandian, S., Farkhondeh, T. and Samini, F. (2017) Honey and health: A review of recent clinical research. Pharmacognosy. Res., 9(2): 121-127.

4. Charalambous, M., Raftopoulos, V., Paikousis, L., Katodritis, N., Lambrinou, E., Vomvas, D., Georgiou, M. and Charalambous, A. (2018) The effect of the use of thyme honey in minimizing radiation-induced oral mucositis in head and neck cancer patients: A randomized controlled trial. Eur. J. Oncol. Nurs., 34(2): 89-97.

5. Takzaree, N., Hassanzadeh, G., Rouini, M.R., Manayi, A., Hadjiakhondi, A. and Majidi Zolbin, M. (2017) Evaluation of the effects of local application of thyme honey in open cutaneous wound healing. Iran. J. Public Health, 46(4): 545-551

6. Charalambous, A., Lambrinou, E., Katodritis, N., Vomvas, D., Raftopoulos, V., Georgiou, M., Paikousis, L. and Charalambous, M. (2017) The effectiveness of thyme honey for the management of treatment-induced xerostomia in head and neck cancer patients: A feasibility randomized control trial. Eur. J. Oncol. Nurs., 27(1): 1-8.

7. Miraj, S. (2016) Antioxidant, anticancer, antimicrobial potential of Origanum vulgare. Pharm. Lett., 8(13): 89-97.

8. Al-Yahya, M., Mothana, R., Al-Said, M., Al-Dosari, M., Al-Musayeib, N., Al-Sohaibani, M., Parvez, M.K. and Rafatullah, S. (2013) Attenuation of CCl4-induced oxidative stress and hepatonephrotoxicity by Saudi Sidr honey in rats. Evid. Based Complement. Alternat. Med., 2013: 569037.
9. Saral, Ö., Yildiz, O., Aliyazicioğlu, R., Yuluğ, E., Canpolat, S., Öztürk, F. and Kolayli, S. (2016) Apitherapy products enhance the recovery of CCL4-induced hepatic damages in rats. Turk. J. Med. Sci., 46(1): 194-202.

10. Al-Waili, N.S., Saloom, K.Y., Al-Waili, T.N., Al-Waili, A.N., Akmal, M., Al-Waili, F.S. and Al-Waili, H.N. (2006) Influence of various diet regimens on deterioration of hepatic function and hematological parameters following carbon tetrachloride: A potential protective role of natural honey. Nat. Prod. Res., 20(13): 1258-1264.

11. El-Haskoury, R., Zizi, S., Touzani, S., Al-Waili, N., Al-Ghamdi, A. and Lyoussi, B. (2016) Diuretic activity of carob (Ceratonia siliqua L.) honey: Comparison with furosemide. Afr. J. Tradit. Complement. Alternat. Med., 12(4): 128-133.

12. Fihri, A., Al-Waili, N., El-Haskoury, R., Bakour, M., Amarti, A. and Ansari, M. (2016) Protective effect of Morocco carob honey against lead-induced anemia and hepato-renal toxicity. Cell. Physiol. Biochem., 39(1): 115-122.

13. Sikander, M., Malik, S., Parveen, K., Ahmad, M., Yadav, D., Hafeez, Z. and Bansal, M. (2013) Hepatoprotective effect of Origanum vulgare in Wistar rats against carbon tetrachloride-induced hepatotoxicity. Protoplasma, 250(2): 483-493.

14. Küçük, M., Kolayli, S., Karaoğlu, S., Ulusoy, E., Baltaci, C. and Candan, F. (2007) Biological activities and chemical composition of three honeys of different types from Anatolia. Food Chem., 100(2): 526-534.

15. AL-Waili, N., Al Ghamdi, A., Ansari, M.J., Al-Attal, Y., Al-Mubarak, A. and Salom, K. (2013) Differences in composition of honey samples and their impact on the antimicrobial activities against drug multiresistant bacteria and pathogenic fungi. Arch. Med. Res., 44(4): 307-316.

16. Bogdanov, S. (2009) Harmonised methods of the international IHC. Bee Prod. Sci., 5(1): 1-62.

17. Naab, O., Tamame, M. and Caccavari, M. (2008) Palynological and physicochemical characteristics of three unifloral honey types from central Argentina. Span. J. Agric. Res., 4(4): 566-576.

18. Terrab, A., Recamales, A., Hernanz, D. and Heredia, F. (2004) Characterization of Spanish thyme honeys by their physicochemical characteristics and mineral contents. Food Chem., 88(5): 537-542.

19. Singleton, V.L. (1964) Colorimetry of Total Phenolics with Phosphomolybdic-Phosphotungstic Acid Reagents. Wiley, New York. p331.

20. Samatha, T., Shyamsundarachary, R., Srinivas, P. and Swamy, N. (2013) Quantification of total phenolic and total flavonoid contents in extracts of Oroxylum indicum L. Kurz. Asian J. Pharm. Clin. Res., 5(3): 177-179.

21. Sugathakumar, E., Santha, M., Hephzibah, P. and Mahalingam, J. (1999) In vitro antioxidant, anti-lipid peroxidation activities and HPLC analysis of methanol extracts from bark and stem of Mahonia leschenaultia takeda. Asian J. Plant. Sci. Res., 3(2): 116-126.

22. Prieto, P., Pineda, M. and Aguilar, M. (1999) Spectrophotometric quantitation of antioxidant capacity through the formation of a phosphomolybdenum complex: Specific application to the determination of Vitamin E. Anal. Biochem., 269(4): 337-341.

23. Brand-Williams, W., Cuvelier, M. and Berset, C. (1995) Use of a free radical method to evaluate antioxidant activity. LWT Food Sci. Technol., 28(1): 25-30.

24. Aljadi, A. and Yusoff, K. (2003) Isolation and identification of phenolic acids in Malaysian honey with antibacterial properties. Turk. J. Med. Sci., 33(4): 229-236.

25. Benziane, D., Boukir, M. and Taouil, R. (2010) Phytochemical analysis and in vitro antibacterial activity of the essential oil of Origanum vulgare from Morocco. Am. Eurasain J. Sci. Res., 5(2): 120-129.

26. Varma, R., Kaushal, R., Junnarkar, A., Thomas, G., Naidu, M., Singh, P., Tripathi, R. and Shridhar, D. 
(1985) Polysorbate 80: A pharmacological study. Arzneimittelforschung, 35(5): 804-808.

27. Llana-Ruiz-Cabello, M., Maisanaba, S., Puerto, M., Pichardo, S., Jos, A., Moyano, R. and Cameán, A. (2017) A subchronic 90-day oral toxicity study of Origanum vulgare essential oil in rats. Food. Chem. Toxicol.,101(1): 36-47.

28. El-Haskoury, R., Kriaa, W., Lyoussi, B. and Makni, M. (2018) Ceratonia siliqua honeys from Morocco: Physicochemical properties, mineral contents, and antioxidant activities. J. Food. Drug Anal., 26(1): 67-73.

29. Aazza, S., Lyoussi, B., Antunes, D. and Miguel, M.G. (2014) Physicochemical characterization and antioxidant activity of 17 commercial Moroccan honeys. Int. J. Food Sci. Nutr., 65(4): 449-457.

30. Moloudian, H., Abbasian, S., Nassiri-Koopaei, N., Tahmasbi, M.R., Afzal, G.A., Ahosseini, M.S., Yunesian, M. and Khoshayand, M.R. (2018) Characterization and classification of Iranian honey based on physicochemical properties and antioxidant activities, with chemometrics approach. Iran. J. Pharm. Res., 17(2): 708-725.

31. Devillers, J., Morlot, M., Pham-Delegue, M.H. and Dore, J.C. (2004) Classification of monofloral honeys based on their quality control data. Food Chem., 86(4): 305-312.

32. Soares, S., Pinto, D., Rodrigues, F., Alves, R.C. and Oliveira, M.B. (2017) Portuguese honeys from different geographical and botanical origins: A 4-Year stability study regarding quality parameters and antioxidant activity. Molecules, 22(8): E1338.

33. Saric, G., Matkovic, D., Hruskar, M. and Vahcic, N. (2008) Characterisation and classification of Croatian honey by physicochemical parameters. Food Technol. Biotechnol., 46(4): 355-367.

34. Mehryar, L., Esmaiili, M. and Hassanzadeh, A. (2013) Evaluation of some physicochemical and rheological properties of Iranian honeys and the effect of temperature on its viscosity. Am. Eurasian. J. Agric. Environ. Sci., 6(9): 807-819.

35. The Council of the European Union. (2002) Council directive 2001/110/EC relating to honey. J. Eur. Commun., 10(1): 47-52.

36. Saxena, S., Gautam, S. and Sharma, A. (2010) Physical, biochemical and antioxidant properties of some Indian honeys. Food Chem., 118(4): 391-397.

37. Aazza, S., Lyoussi, B., Antunes, D. and Miguel, M.G. (2013) Physicochemical characterization and antioxidant activity of commercial Portuguese honeys. J Food. Sci., 78(8): C1159-C1165.

38. Stagos, D., Soulitsiotis, N., Tsadila, C., Papaeconomou, S., Arvanitis, C., Ntontos, A., Karkanta, F., AdamouAndroulaki, S., Petrotos, K., Spandidos, D.A., Kouretas, D. and Mossialos, D. (2018) Antibacterial and antioxidant activity of different types of honey derived from Mount Olympus in Greece. Int. J. Mol. Med., 42(2): 726-734.

39. Taha, M., Rababah, R., Brewer, S., Alhamad, M., Yang, W., Alrababah, M. and Al-Ghzawi, A. (2014) Total phenol, antioxidant activity, flavonoids, anthocyanins and color of honey as affected by floral origin found in the arid and semiarid Mediterranean areas. J. Food Process. Preserv.
38(12): 1119-1128.

40. Alissandrakis, E., Tarantilis, P.A., Harizanis, P.C. and Polissiou, M. (2007) Comparison of the volatile composition in thyme honeys from several origins in Greece. $J$. Agric. Food Chem., 55(20): 8152-8157.

41. Khalil, M.I., Alam, N., Moniruzzaman, M., Sulaiman, S.A. and Gan, S.H. (2011) Phenolic acid composition and antioxidant properties of Malaysian honeys. J. Food Sci., 76(6): C921-C928.

42. McKelvey, K.J. and Appleton, I. (2012) Epicatechin gallate improves healing and reduces scar formation of incisional wounds in Type 2 diabetes mellitus rat model. Wounds, 24(3): 55-57.

43. Kapoor, M., Howard, R., Hall, I. and Appleton, I. (2004) Effects of epicatechin gallate on wound healing and scar formation in a full thickness incisional wound healing model in rats. Am. J. Pathol., 165(1): 299-307.

44. Al-Sayed, E. and Abdel-Daim, M.M. (2018) Analgesic and anti-inflammatory activities of epicatechin gallate from Bauhinia hookeri. Drug Dev. Res., 79(4): 157-164.

45. Tian, H. and Lai, D.M. (2006) Analysis on the volatile oil in Origanum vulgare. Zhongyaocai, 29(9): 920-921.

46. Vale-Silva, L., Silva, M.J., Oliveira, D., Gonçalves, M.J., Cavaleiro, C., Salgueiro, L. and Pinto, E. (2012) Correlation of the chemical composition of essential oils from Origanum vulgare subsp. virens with their in vitro activity against pathogenic yeasts and filamentous fungi. J. Med. Microbiol., 61(4): 252-260.

47. Teixeira, B., Marques, A. and Ramos, C. (2013) Chemical composition and antibacterial and antioxidant properties of commercial essential oils. Ind. Crops Prod., 43(7): 587-595.

48. Han, F., Ma, G.Q., Yang, M., Yan, L., Xiong, W., Shu, J.C., Zhao, Z.D. and Xu, H.L. (2017) Chemical composition and antioxidant activities of essential oils from different parts of the oregano. J. Zhejiang Univ. Sci. B, 18(1): 79-84.

49. Stanojević, D., Stanojević, J. and Cvetković, D. (2016) Antioxidant activity of oregano essential oil (Origanum vulgare L.). Biol. Nyssana, 7(2): 131-139.

50. Sikander, M., Malik, S., Parveen, K., Ahmad, M., Yadav, D., Hafeez, Z.B. and Bansal, M. (2013) Hepatoprotective effect of Origanum vulgare in Wistar rats against carbon tetrachloride-induced hepatotoxicity. Protoplasma, 250(2): 483-493.

51. Jaramillo-Juárez, F., Rodriguez-Vázquez, M.L., RincónSánchez, A.R., Consolación Martinez, M., Ortiz, G.G. and Llamas, J. (2008) Acute renal failure induced by carbon tetrachloride in rats with hepatic cirrhosis. Ann. Hepatol., 7(4): 331-338.

52. Marimuthu, S., Adluri, R.S., Rajagopalan, R. and Menon, V.P. (2013) Protective role of ferulic acid on carbon tetrachloride-induced hyperlipidemia and histological alterations in experimental rats. J. Basic Clin. Physiol. Pharmacol., 24(1): 59-66.

53. Sharifi-Rad, M., Varoni, E.M., Iriti, M., Martorell, M., Setzer, W.N., Del Mar Contreras, M., Salehi, B., SoltaniNejad, A., Rajabi, S., Tajbakhsh, M. and Sharifi-Rad, J. (2018) Carvacrol and human health: A comprehensive review. Phytother. Res., 32(9): 1675-1687. 